LAWRENCE LIVERMORE N A T IO N A L LABORATORY

\section{Neutron-Induced Reactions and Spectroscopy with GEANIE}

John A. Becker, R. O. Nelson

January 14, 2005

International Conference on Nuclear Data for Science and Technology

Santa Fe, NM, United States

September 26, 2004 through October 1, 2004 
This document was prepared as an account of work sponsored by an agency of the United States Government. Neither the United States Government nor the University of California nor any of their employees, makes any warranty, express or implied, or assumes any legal liability or responsibility for the accuracy, completeness, or usefulness of any information, apparatus, product, or process disclosed, or represents that its use would not infringe privately owned rights. Reference herein to any specific commercial product, process, or service by trade name, trademark, manufacturer, or otherwise, does not necessarily constitute or imply its endorsement, recommendation, or favoring by the United States Government or the University of California. The views and opinions of authors expressed herein do not necessarily state or reflect those of the United States Government or the University of California, and shall not be used for advertising or product endorsement purposes. 


\title{
Neutron-Induced Reactions and Spectroscopy with GEANIE
}

\author{
J. A. BECKER ${ }^{*}$ and R. O. NELSON ${ }^{\dagger}$ \\ *Lawrence Livermore National Laboratory Livermore, CA 94550, USA \\ ${ }^{\dagger}$ LANSCE-3, Los Alamos National Laboratory Los Alamos, NM 87545, USA
}

\begin{abstract}
A large number of partial $\gamma$-ray cross sections produced in neutron-induced reactions with neutrons in the energy range $1<\mathrm{E}_{\mathrm{n}}(\mathrm{MeV})<200$ have been measured over the past eight years. Partial $\gamma$-ray cross sections are measured as a function of incident neutron energy using the time-of-flight technique. Reaction channel cross sections were deduced from these measurements with the aid of nuclear modeling. Enabling facilities are the intense "white" source of neutrons at the LANSCE/WNR 60R 20-meter flight path, and the precision $\gamma$-ray spectrometry of the Compton-suppressed Ge detector array GEANIE. The first focus of the measurements was on the ${ }^{239} \mathrm{Pu}(\mathrm{n}, 2 \mathrm{n}) \mathrm{cross}$ section, followed by a series of other experiments on nuclei throughout the periodic table, with an emphasis on neutronfluence activation detectors (or "RadChem detectors"). Representative measurements will be presented, along with the techniques. Experiments in progress and future plans are mentioned.
\end{abstract}

\section{INTRODUCTION}

Neutron-induced reaction data for a wide variety of samples have been gathered taking advantage of the GEANIE (Germanium Array for Neutron-Induced Excitations) spectrometer sited at the Los Alamos Neutron Science Center's (LANSCE) WNR. Absolute partial $\gamma$-ray cross sections are measured for discrete $\gamma$ ray production caused by the interaction of energetic neutrons. The $\gamma$-rays are measured in GEANIE, a Compton-suppressed array of high-resolution $\left(\Delta \mathrm{E}_{\gamma} / \mathrm{E}_{\gamma}\right.$ $\sim 2 / 1000$ ) Ge detectors. The pulsed "white" neutron beam is produced by LANSCE/WNR, $800-\mathrm{MeV}$ protons striking a tungsten target. GEANIE is located on the WNR 60 degree right (60R) flight path, and $E_{n}$ for an event is determined with the time-of-flight technique. The flight path is $\sim 20 \mathrm{~m}$.

The goals of this now 8-year-old project focused at first on deduction of the $n, 2 n$ cross section on the actinides samples ${ }^{239} \mathrm{Pu}$ and ${ }^{235} \mathrm{U}$. The $n, 2 n$ cross sections [1-3] were deduced from the measured $\gamma$-ray partial cross sections with an appeal to very careful and painstaking nuclear modeling using enhanced Hauser-Feshbach reaction codes. Inelastic scattering and the $n, 3 n$ reaction were measured for ${ }^{238} \mathrm{U}$ at the same time [4]. The emphasis switched to samples of diagnostic "detector" nuclides following the actinide studies, with an emphasis on neutron-induced reactions on ${ }^{89} \mathrm{Y},{ }^{90} \mathrm{Zr}$, ${ }^{191} \mathrm{Ir}$, and ${ }^{193} \mathrm{Ir}$ [5-9], although many other samples were studied. Some studies have focused on nuclear structure [10-11] and others focused on neutron cross section standards - the contribution of Nelson, et al., [12] to this conference. To date, 31 different samples have been studied at GEANIE.

A close collaboration between nuclear theorists and experimentalists marked the nearly decade long effort to address these issues from its inception, and continuing through the present time. Details of the enabling facilities can be found in $[13,14]$. The next sections describe a few features of the experimental arrangement, the irradiated samples, representative results, and potential efforts.

\section{ENABLING FACILITY}

GEANIE at LANSCE/WNR is a unique facility: A large Compton-suppressed Ge detector array sited on a 20-m neutron time-of-flight path with an intense energetic neutron flux, increased since 1996 by $3 \times$ to $\sim 10^{4}$ neutrons $/ \mathrm{cm}^{2} / \mathrm{s}$ in a $1 \mathrm{MeV}$ bin at $\mathrm{E}_{\mathrm{n}}=10 \mathrm{MeV}$. Characteristics of the neutron beam pulse structure are given in many places, including at this conference [8]. Features of GEANIE measurements include: 
- Cross sections are measured as a function of $\mathrm{E}_{\mathrm{n}}$, for $1<\mathrm{E}_{\mathrm{n}}(\mathrm{MeV})<200$, including the incident neutron region $9<\mathrm{E}_{\mathrm{n}}(\mathrm{MeV})<14$, difficult for "monoenergetic" neutron production sources.

- The GEANIE array itself is evolved from the HERA array developed by Deleplanque, Diamond, and Stephens at LBNL. HERA was transferred from DOE/OS to DOE/DP in 1996. The array was augmented by 10 Planar Ge detectors at LANSCE to increase the capability for $100-800 \mathrm{keV} \gamma$-ray spectroscopy in a background of scattered neutrons.

- Time intervals up to the $8.3 \mathrm{~ms}$ between protonbeam macro pulses can be used to measure decay radiation, often providing in-place $\gamma$-ray efficiency calibrations using well-measured $\beta$-decay radiation. Alternatively, lifetimes in this region can be measured.

The electronics and software of the data acquisition system are described elsewhere; the data transfer from CAMAC crate to computer is based on the MSU $4 \pi$ System. All detector channels including the fissionchamber flux monitor are treated identically. This was a key concept of the data acquisition system, with the result that relative measurements are very accurate. The neutron flight path is well shielded, and the location on $60 \mathrm{R}$ provides a lower-background environment than on some of other WNR flight paths.

\section{METHOD}

Fig. 1 illustrates our method for extracting reaction channel cross sections. The example is for the ${ }^{239} \mathrm{Pu}(\mathrm{n}, 2 \mathrm{n})$ cross section. We measure energies and yields of discrete cascade $\gamma$-rays; the reaction channel is identified on the basis of known (characteristic) $\gamma$ ray energies. [Fig. 1(a)]. Yields are converted to partial $\gamma$-ray cross section [Fig. 1(b)] using calibrated detector efficiency, deadtime corrections, neutron flux, and target thickness. Fig. 1(c) illustrates schematically the conversion of $\sigma\left(\gamma_{i}\right)$ to $\sigma(n, 2 n)$ with the aid of enhanced Hauser-Feshbach model calculations which predict the relationship between each $\sigma\left(\gamma_{i}\right)$ and $\sigma(n, 2 n)$. In practice, an averaging was done, since the reaction model calculations are, in general, imprecise for the individual $\sigma\left(\gamma_{\mathrm{i}}\right)$ [2]. The transformation depends less on the modeling input, the lower down in excitation energy the measurements are made [Fig. 1(c)]. For example, the $4_{1}{ }^{+} \rightarrow 2_{1}{ }^{+}$transition in the ground state band provides $\sim 80 \%$ of the cross section at $10 \mathrm{MeV}$, and the model $\sim 20 \%$, while the $8_{1}^{+} \rightarrow 6_{1}^{+}$transition provides $\sim 10 \%$ of the cross section directly with $90 \%$ owing to modeling. Fig. 2(a) shows the cross section for ${ }^{239} \mathrm{Pu}(\mathrm{n}, 2 \mathrm{n})$.

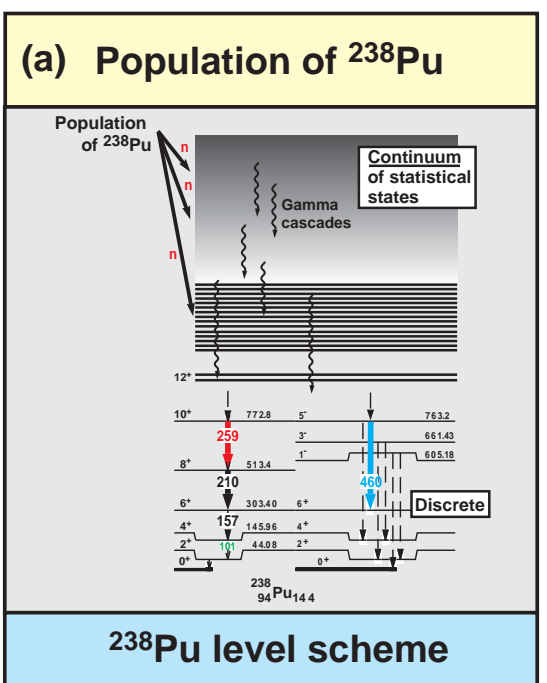

P02821-jab-u-002
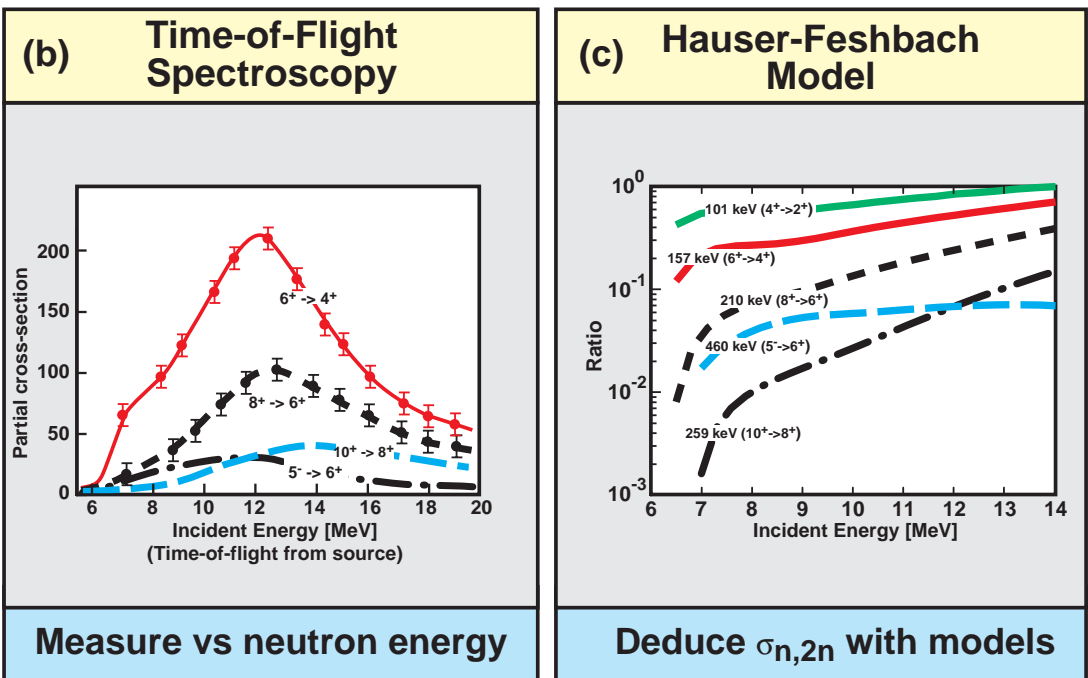

FIG. 1. Schematic illustrations of ${ }^{238} \mathrm{Pu}$ population in the ${ }^{239} \mathrm{Pu}(\mathrm{n}, 2 \mathrm{n})$ reaction (a), partial $\gamma$-ray cross sections $\sigma\left(\gamma_{\mathrm{i}}\right)$ deduced from yields of discrete $\gamma$-rays at low excitation energy (b), and the transformation of $\sigma\left(\gamma_{\mathrm{i}}\right)$ to $\sigma(n, 2 n)$ using predications of enhanced Hauser-Feshbach reaction theory (c). 


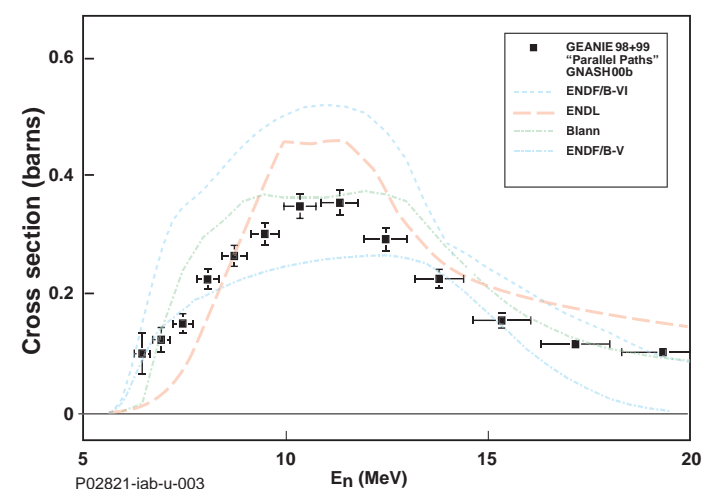

FIG. 2. The ${ }^{239} \mathrm{Pu}(\mathrm{n}, 2 \mathrm{n}){ }^{238} \mathrm{Pu}$ cross section deduced from the GEANIE measurements [1,2] compared with prior evaluations.

\section{Mixed Sample Technique}

The precision energy determination and line shape characteristics of the Compton-suppressed $\mathrm{Ge}$ detectors allow the use of mixed samples and simultaneous measurement of cross sections for different nuclides, since the $\gamma$-rays can be related to the corresponding sample. We began the practice of including natural iron foils (typically on each side of the sample), measuring the yield of the ${ }^{56} \mathrm{Fe}\left(2_{1}{ }^{+} \rightarrow 0_{1}{ }^{+}\right)$ transition, a standard cross section [15]. This procedure gives confidence in the experimental arrangement and data reduction (and if required a normalization). The Fe cross section values have been more accurately determined in our work. We find the Simakov value to be high by about $10 \%$ to $705 \mathrm{mb}$ at $\mathrm{E}_{\mathrm{n}}=14 \mathrm{MeV}$, following Nelson et al. [12].
Cross section results for some RadChem detectors are presented next: Fig. 3 illustrates the results [9] for ${ }^{193} \operatorname{Ir}\left(\mathrm{n}, \mathrm{n}^{\prime}\right)^{193 \mathrm{~m}} \mathrm{Ir}$, i.e., population of the ${ }^{193} \mathrm{Ir}$ isomer with $\mathrm{E}_{\mathrm{x}}=80 \mathrm{keV}$ by inelastic neutron scattering. Results of the GEANIE team are compared with the earlier activation results of Bayhurst, et al., [16] and the 1998 ENDF Evaluation. The use of the "white" source coupled with the time-of-flight technique to expose the shape of the cross section as a function of incident neutron energy $\left(E_{n}\right)$ is nicely illustrated in Fig. 3.

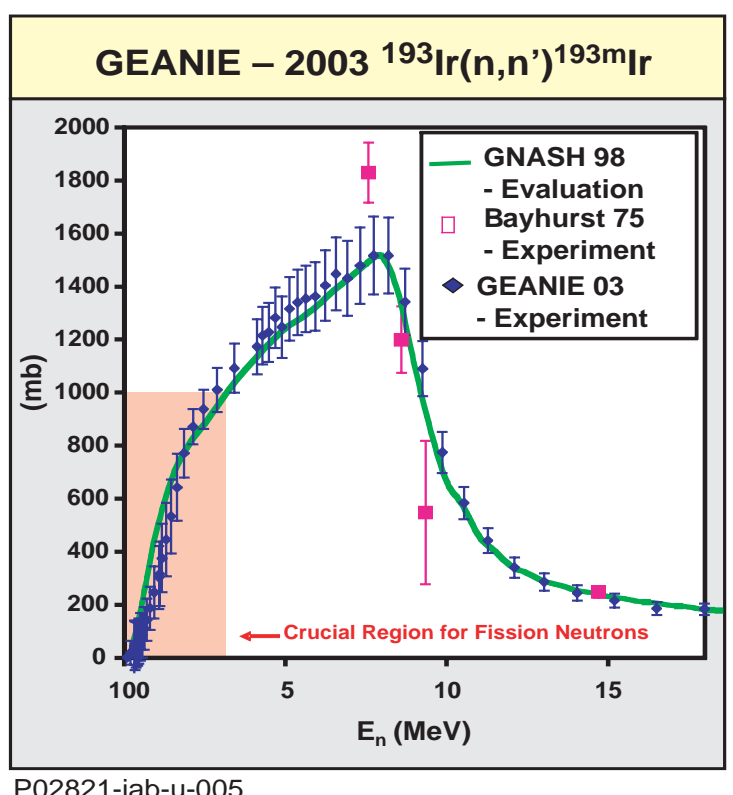

FIG. 3. The cross section for production of the Ir-193 isomer $\left({ }^{193 \mathrm{~m}} \mathrm{Ir}\right)$ at $\mathrm{E}_{\mathrm{x}}=80 \mathrm{keV}[9]$.

\section{ILLUSTRATIVE RESULTS}
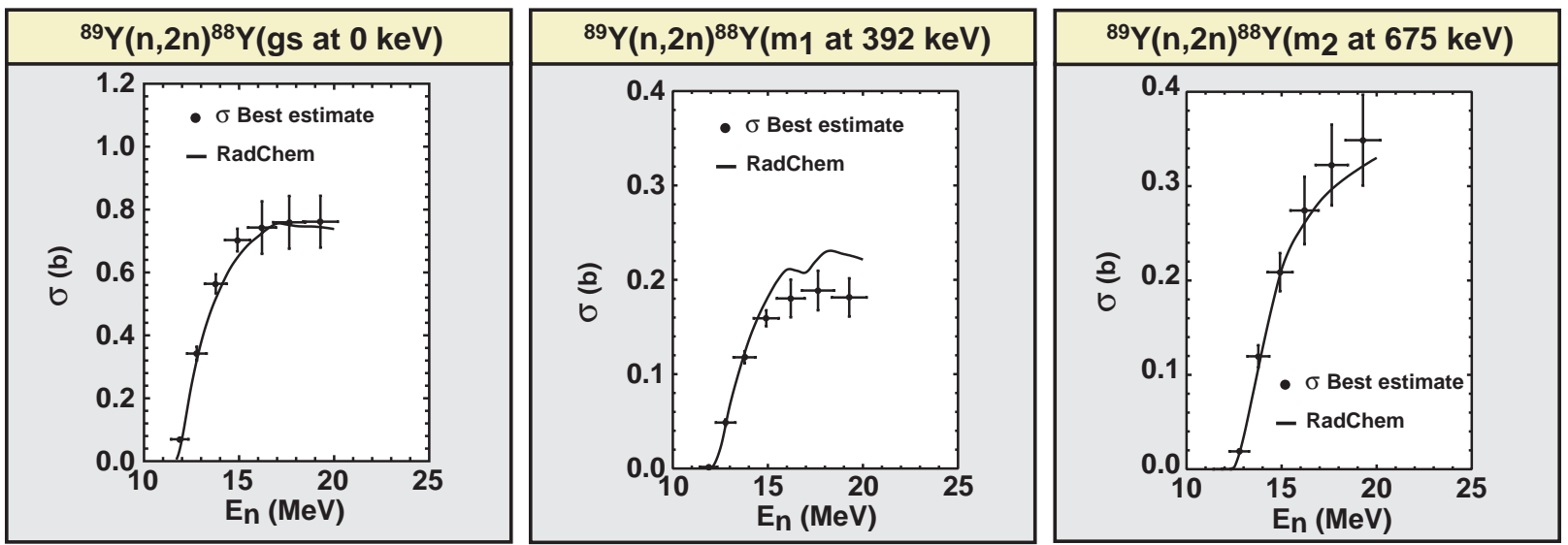

P02821-jab-u-006

FIG. 4. The ${ }^{89} \mathrm{Y}(\mathrm{n}, 2 \mathrm{n})$ cross section decomposed into 3 components corresponding to production of ${ }^{88} \mathrm{Y}$ in its ground state, " $\mathrm{m} 1$ " isomer at $392 \mathrm{keV}$, and " $\mathrm{m} 2$ " isomer at $675 \mathrm{keV}$. [5,6]. 
Fig. 4 illustrates the advantage of the GEANIE experimental arrangement to deduce ground state and isomer cross sections $[5,6] .{ }^{235} \mathrm{U}$ fission has been studied both through $\gamma$-ray measurements with "thick" samples [17] and through x-rays using "thin" ${ }^{235,238} \mathrm{U}$ deposits on solar-cell fission detectors [1819]. Fig 5 shows (preliminary) results [10] for a rotational band in ${ }^{197} \mathrm{Au}$ based on the $11 / 2^{-}$isomer in ${ }^{197} \mathrm{Au}$. We close this section with 2 cross section examples obtained with ${ }^{150} \mathrm{Sm}$ and ${ }^{75} \mathrm{As}$ samples.

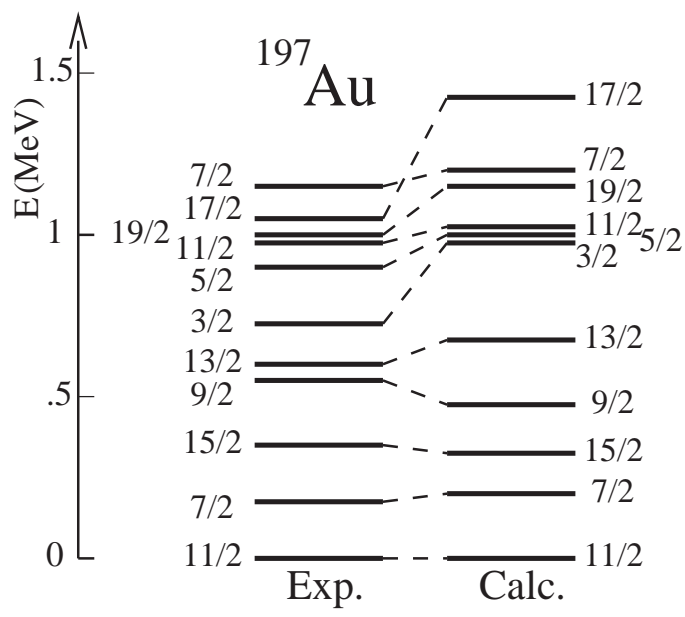

Fig. 5. Newly-established ${ }^{197} \mathrm{Au} \pi=$ “_." states above the $11 / 2^{-}$isomer compared with preliminary particle-plustriaxial-rotor model calculations $\left(\beta=0.13\right.$ and $\left.\gamma=45^{\circ}\right)$ done by K. Starosta (Private communication, 2004).

Fig. 6 illustrates the ${ }^{150} \mathrm{Sm}(\mathrm{n}, 2 \mathrm{n}){ }^{149} \mathrm{Sm}$ cross section [20], and Fig. 7 shows the measured cross section for isomer production in the ${ }^{75} \mathrm{As}(\mathrm{n}, 2 \mathrm{n})$ reaction [21].

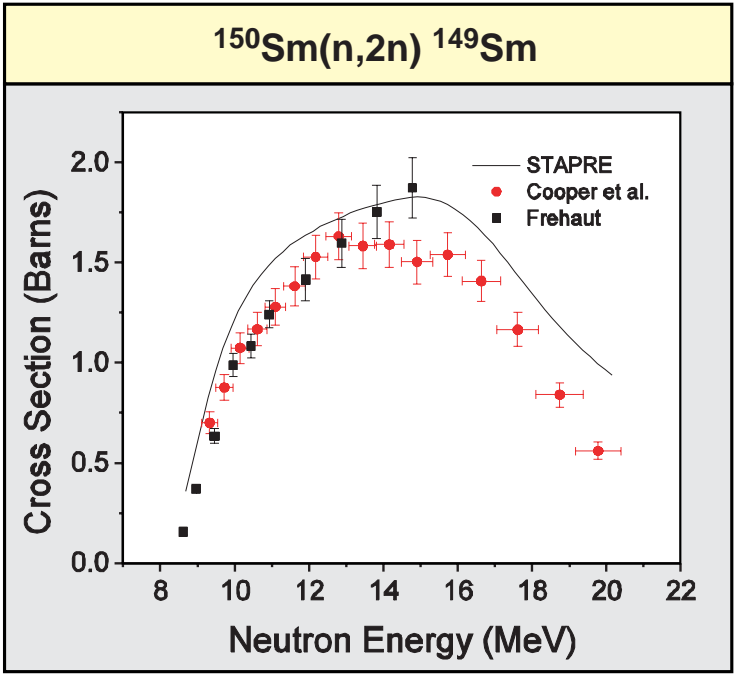

P02821-jab-u-007

FIG. 6. The ${ }^{150} \mathrm{Sm}(\mathrm{n}, 2 \mathrm{n})$ cross section [20] compared to the measurements of Frehaut, et al. [22] and the prediction made with the STAPRE code [23].
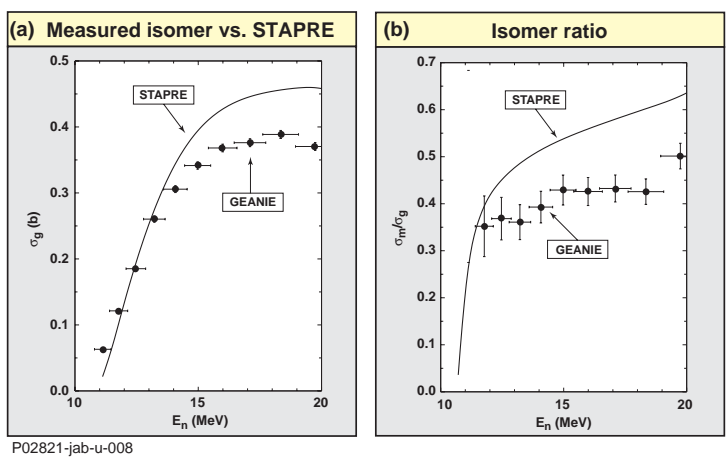

FIG. 7. Production of the ${ }^{74} \mathrm{As}$ isomer at $259 \mathrm{keV}$ via the ${ }^{75} \mathrm{As}(\mathrm{n}, 2 \mathrm{n})$ reaction.

\section{FUTURE ACTIVITIES}

\section{${ }^{48} \mathrm{Ti}+\mathrm{n}$ reaction study}

A study of ${ }^{48} \mathrm{Ti}+\mathrm{n}$ is being completed as a Ph.D. thesis for Dugersuren Dashdorj [24] (G.E. Mitchell, North Carolina State University, Major Professor). ${ }^{48} \mathrm{Ti}$ is one of the lighter nuclei we have studied at GEANIE. Reaction model cross-section predictions for the several open light particle-emission channels are being compared with measurements (See Fig. 8). 


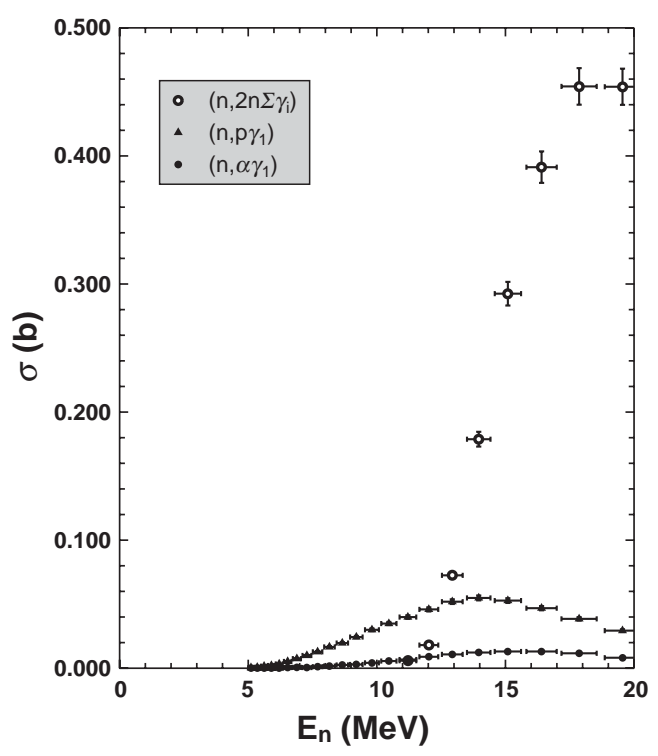

Fig. 8. Unpublished preliminary results for several outgoing channels for $n+{ }^{48}$ Ti reactions [24].

\section{Preequilibrium}

The preequilibrium reaction mechanism is the usual explanation invoked to explain the high energy neutrons (as opposed to boil-off neutrons) which are emitted as the incident neutron energy increases above $B_{n}$. The residual nucleus is left at lower excitation energy where the level density is low, and low-spin states are generally dominant. Most of the evidence for preequilibrium comes from fast neutron spectroscopy. The data in Fig. 9 suggest evidence in the $\gamma$-ray channel for preequilibrium particle emission. Fig. 9 (a) and (b) compare the population of the ${ }^{90} \mathrm{Zr}{ }_{1}{ }^{+}$state and the $6_{1}{ }^{+}$state, divided by the inelastic channel cross section [7]. As the neutron energy increases beyond $15 \mathrm{MeV}$, the ratio for the $2_{1}{ }^{+}$state increases, and the corresponding ratio for the $6_{1}{ }^{+}$state decreases. We plan further exploration of preequilibrium in bombardments of ${ }^{186} \mathrm{~W}$ and of ${ }^{170} \mathrm{Er}$, where shell structure plays less of a role in data interpretation than in ${ }^{90} \mathrm{Zr}$.
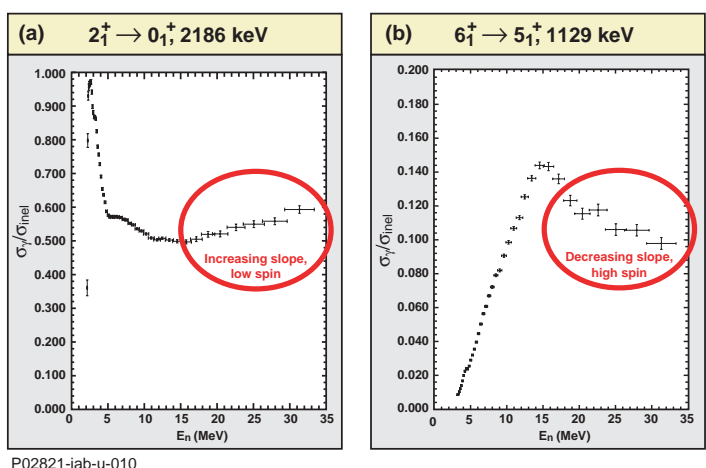

FIG. 9. Cross section ratios for ${ }^{90} \mathrm{Zr}\left(\mathrm{n}, \mathrm{n}^{\prime}\right), \sigma\left(2_{1}^{+}\right) / \sigma\left(\mathrm{n}, \mathrm{n}^{\prime}\right)$ (a), and $\sigma\left(6_{1}^{+}\right) / \sigma\left(\mathrm{n}, \mathrm{n}^{\prime}\right)$ in (b). Data from Ref. [7].

\section{Isomer studies and searches}

We have the capability to measure properties of isomeric states with lifetimes in the range, $\sim 1 \mu \mathrm{s}<$ $\tau_{1 / 2}<10 \mathrm{~ms}$. The result of a lifetime measurement [25] for the 797- $\mathrm{keV}$ transition in the $\mathrm{K}^{\pi}=19 / 2^{+}$ decay chain in ${ }^{175} \mathrm{Lu}$ is shown in Fig. 10. Time is measured relative to the end of the LANSCE proton accelerator macro pulse.

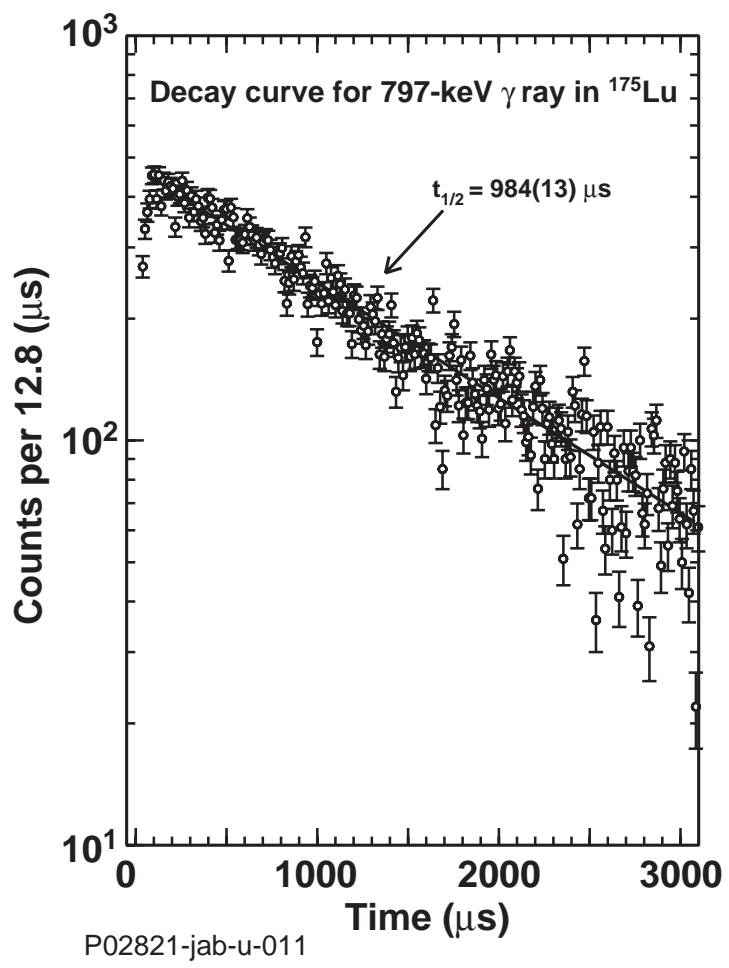

FIG. 10. Decay curve for the $797 \mathrm{keV} \gamma$-ray in ${ }^{175} \mathrm{Lu}$ [25]. 


\section{GEANIE IMPROVED}

An array of 4-6 suppressed "clover" Ge detectors coupled with the present GEANIE planar detectors offers significantly more efficiency than the present GEANIE array. The coaxial detectors of GEANIE are approaching 20 years of service; they are typically $20-25 \%$ efficient (compared to a 3 " $\times 3$." right cylindrical $\mathrm{NaI}(\mathrm{Tl})$ detector for $\left.\mathrm{E}_{\gamma}=1.33 \mathrm{MeV}\right)$. An array of "clover" detectors (4 or more), with suppression shields offers the same or more efficiency for $500-\mathrm{keV} \gamma$-rays, and significantly increased efficiency for $1.5 \mathrm{MeV}$ and higher-energy $\gamma$-rays. This "improved" GEANIE makes significantly more efficient use of beam time.

\section{CONCLUSION}

The combination of a powerful Comptonsuppressed Ge detector array and the pulsed intense neutron source at LANSCE/WNR provides new nuclear data, and gives experimentalists the opportunity to gain information on the preequilibrium reaction mechanism, with the result of improved models of nuclear reactions - important physics. With an upgraded GEANIE, the measured physical data will be improved due to the greater detection efficiency for $>1 \mathrm{MeV} \gamma$-rays - important for example in the spectroscopy of both actinide and for nuclei near $\mathrm{A}=50$ and 90 where shell effects are important and $\mathrm{MeV} \gamma$-ray energies are typical of vibrational decay.

\section{ACKNOWLEDGMENTS}

Contributors include: J. R. Cooper, D. Dashdorj, M. Devlin, N. Fotiades, P. E. Garrett, and W. Younes, currently active in the program, and D. Archer, L. A. Bernstein, G. Johns, C. A. McGrath, and D. P. McNabb, past group members. Greg Chaparro has provided technical support from project inception. We have enjoyed especially close collaboration with M. Chadwick, P. Young, and T. Kawano. M. Kreisler, S. Sterbenz, D. D. Strottman, and $\mathrm{S}$. Wender have actively supported this project.

Work performed under the auspices of the U.S. DoE by the University of California, Los Alamos National Laboratory (W-7405-ENG-36) and Lawrence Livermore National Laboratory (W-7405ENG-48), and benefited from use of the Los Alamos Neutron Science Center (W-7405-ENG-36).

\section{REFERENCES}

1. J. A. Becker, et al., Journal of Nuclear Science and Technology (ed. K. Shibata), Supplement 2, 620 (2002).

2. L. A. Bernstein, et al., Phys. Rev. C 65, 021601(R) (2002).

3. W. Younes, et al., UCRL-ID-140313 (2000).

4. N. Fotiades, et al., Phys. Rev. C 69, 024601 (2004)

5. M. B. Chadwick, et al., Proceedings of the Nuclear Explosives Design Physics Conference, in press (2004). LA-UR-03-9143.

6. P. E. Garrett, et al., UCRL-ID-153190; LA-UR-037738.

7. P. E. Garrett, et al., Phys. Rev. C 68024312 (2003).

8. N. Fotiades, et al., in Proceedings of International Conference on Nuclear Data for Science and Technology, Santa Fe, NM Sept. 26 - Oct. 1, 2004.

9. R. O. Nelson, et al., Proceedings of the Nuclear Explosives Design Physics Conference, in press (2004). LA-UR-04-0387.

10. Fotiades, et al., Rotational bands in ${ }^{197} \mathrm{Au}$ based on the $11 / 2$ isomer. Manuscript in preparation.

11. E. Tavukcu, et al., Phys. Rev. C 65, 064309 (2002); P. E. Garrett, et al., Phys. Rev. C 62, 014307 (2000), LAUR-00-13412.

12. R. O. Nelson, Proceedings of International Conference on Nuclear Data for Science and Technology, Santa Fe, NM Sept. 26 - Oct. 1, 2004. LA-UR-04-6799.

13. J. A. Becker and R. O. Nelson, Nuclear Physics News 7 11 (1997).

14. R. O. Nelson, et al., Italian Physical Society Conference Proceedings 59, 445, 1997.

15 S. P. Simakov, A. Pavlik, H. Vonach, and S. Hlavac, IAEA Report INDC (CCP)-413 (1998).

17. B. P. Bayhurst, et al., Phys. Rev. C 12, 451 (1975).

18. W. Younes, et al., Phys. Rev. C 64, 054613 (2001).

19. T. Ethvignot, et al., Journal of Nuclear Science and Technology (ed. K. Shibata), Supplement 2, 254 (2002).

20. T. Ethvignot, et al., Nucl. Instrum. Meth. A490, 559 (2002), LA-UR-02-2234.

21. J. R. Cooper, et al., UCRL-TR-205760/LA-UR-045677 (2004).

22. W. Younes, P. E. Garrett, J. A. Becker, L. A. Bernstein, W. E. Ormand, F. S. Dietrich, R. O. Nelson, M. Devlin, and N. Fotiades, UCRL-ID-154061, 2003. LA-UR-03-7737.

23 J. Frehaut et al., Nucl. Sci. Eng. 74, 29 (1980).

24 R. Hoffman, private communication (2004).

23. D. Dashdorj, private communication (2004).

24. P. E. Garrett, et al., Phys. Rev. C 69, 017302 (2004). 